\title{
Value of TIMI Risk Score Combined With Global Longitudinal Strain for Predicting Major Adverse Cardiac Events After PCl in Patients With ST- Segment Elevation Myocardial Infarction
}

\section{De Bin Yang}

JiaDing Hospital Shanghai: Jiading District Central Hospital Affiliated Shanghai University of Medicine \& Health Sciences

\section{Ying Chun Wang}

JiaDing Hospital Shanghai: Jiading District Central Hospital Affiliated Shanghai University of Medicine \& Health Sciences

\section{Wen Ye Zhu}

JiaDing Hospital Shanghai: Jiading District Central Hospital Affiliated Shanghai University of Medicine \& Health Sciences

\section{Jing Wang}

JiaDing Hospital Shanghai: Jiading District Central Hospital Affiliated Shanghai University of Medicine \& Health Sciences

\section{Lou Jin Rong}

JiaDing Hospital Shanghai: Jiading District Central Hospital Affiliated Shanghai University of Medicine \& Health Sciences

Min Lu ( $\square$ lumin215@163.com)

JiaDing Hospital Shanghai: Jiading District Central Hospital Affiliated Shanghai University of Medicine \& Health Sciences https://orcid.org/0000-0002-7231-467X

\section{Research Article}

Keywords: ST-segment elevation myocardial infarction, TIMI risk score lobal longitudinal strain, ajor adverse cardiac events

Posted Date: September 9th, 2021

DOI: https://doi.org/10.21203/rs.3.rs-838522/v1

License: (c) (1) This work is licensed under a Creative Commons Attribution 4.0 International License. Read Full License 


\section{Abstract}

\section{Purpose}

Accurately assessing the predicting prognosis is important in ST-segment elevation myocardial infarction (STEMI). This study aimed to investigate the predictive value of the TIMI risk score combined with GLS for the occurrence of major adverse cardiovascular events (MACEs)in STEMI patients after percutaneous coronary intervention $(\mathrm{PCl})$

\section{Methods}

Acute STEMI diagnosed between January 2019 to June 2021 were prospectively enrolled. GLS were performed to assess left ventricular dysfunction three days post-percutaneous coronary intervention (PCl). In a 12-month follow up, three prognostic models for MACE were established based on TIMI risk score alone, TIMI risk score + GLS, and TIMI risk score + GLS + clinical risk factors, respectively, and assessed for efficiency.

Results

A total of 138 patients were enrolled. According to the follow-up results, the incidence of MACE in the patients was $19.6 \%$ (27/138). Areas under the receiver operating characteristic (ROC) curves were 0.703 , 0.810 and 0.815 , respectively, in TIMI risk score alone, TIMI risk score + GLS, TIMI risk score + GLS + clinical risk factors, indicating a significantly higher value and more efficient assessment for TIMI risk score + GLS.

Conclusion

Compared with the TIMI risk score alone, TIMI risk score combined with GLS provides a more efficient assessment of risk for determining the prognosis of STEMI patients.

\section{Introduction}

Acute ST-segment elevation myocardial infarction (STEMI) is one of the most common acute and critical diseases in clinical practice. It is characterized by rapid onset, high morbidity, severity and a high mortality rate. Although significant progress has been made in the treatment of STEMI, different major adverse cardiac events (MACEs) can still occur [1,2]. Therefore, adequate individual risk assessment after vascular reconstruction has important clinical significance. Currently, the Thrombolysis in Myocardial Infarction (TIMI) score is a convenient and practical method for determining the clinical prognosis of STEMI patients $[3,4]$. However, it cannot identify all high-risk patients, especially in the case of adverse events in the first year after STEMI [5]. Therefore, we evaluated the efficacy of including objective indicators to support and strengthen the predictive role of the TIMI risk score and provide a more accurate risk stratification tool for clinical practice. 
Left ventricular systolic function is the main indicator for the prognosis of acute myocardial infarction, and it can be used to predict short-term (during hospitalization) and long-term (after discharge) adverse cardiovascular events in high-risk populations [6, 7]. Among the many echocardiographic parameters for evaluating left ventricular function, left ventricular ejection fraction (LVEF) is the simplest and most widely used method for measuring left ventricular systolic function; it is used in the risk assessment and management of many cardiovascular diseases [8]. Studies [9] have found that the combination of LVEF and TIMI risk scores can predict short-term and long-term mortality better than TIMI risk scores alone.

However, use of the LVEF parameter is limited by technical challenges related to left ventricular cavity boundary tracking and geometric assumptions. Therefore, LVEF has inherent limitations [10]. Studies [11, 12] have shown that LVEF is not the most powerful indicator of left ventricular function.

Different from LVEF volume measurement, the global longitudinal strain (GLS) obtains the motion information of the myocardial tissue based on echocardiographic speckle tracking of the endocardial boundary to evaluate the myocardial deformation ability. GLS is not affected by the direction of the sound beam and exhibits excellent accuracy. Compared with LVEF, it has the advantages of better reproducibility and early detection of left ventricular dysfunction $[8,13]$. GLS is a feasible alternative to LVEF for measuring cardiac function in clinical practice. Many studies have confirmed the value of GLS in the evaluation of cardiac function in STEMI patients, but the interaction between GLS and the TIMI risk score for predicting prognosis has not been reported. Therefore, we hypothesized that GLS was better able to predict MACEs than LVEF and that this difference could enhance risk stratification using the TIMI risk score. The purpose of this study was to investigate whether the inclusion of GLS in the TIMI risk score has greater prognostic value for the occurrence of MACEs in STEMI patients after percutaneous coronary intervention $(\mathrm{PCl})$.

\section{Materials And Methods}

\section{Patients}

This was a review study. 138 Patients diagnosed with STEMI between January 2019 to June 2021, and underwent emergent $\mathrm{PCl}$ in the Jiading Central Hospital were included in this prospective study.

Inclusion criteria were: diagnosis of STEMI and planned emergent PCI.

Exclusion criteria were: 1) severe emphysema, pulmonary fibrosis, or other breathing problems that impeded breath holding, and 2) poor image quality in GLS and regular echocardiography images.

This work has been carried out in accordance with the Declaration of Helsinki (2000) of the World Medical Associatio. The present study was approved by the Ethics Committee of Jiading Central Hospital [2019-B-15]. All the included patients provided signed informed consent.

\section{TIMl risk scoring method}


An electronic case report form was used to collect demographic and clinical data, including variables for estimating the TIMI risk score. At present, a TIMI risk score of $0-3$ is generally considered low risk, 4-6 is considered moderate risk, and $7-14$ is considered high risk. The TIMI risk score is determined as follows [9]: $\otimes$ age $65-74$ years ( 2 points), $\geq 75$ years ( 3 points); $\otimes$ systolic blood pressure $<100 \mathrm{mmHg}$ ( $1 \mathrm{mmHg}=$ $0.133 \mathrm{kPa}$ ) (3 points); and $\otimes$ heart rate $>100$ beats $/ \mathrm{min}$. ( 2 points); $\otimes$ Killips grade II-IV cardiac function ( 2

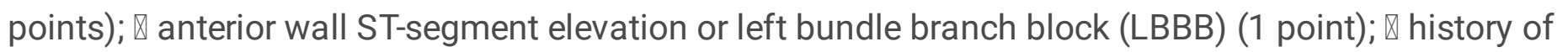
diabetes, hypertension or angina pectoris (1 point); (8) body weight $<67 \mathrm{~kg}$ (1 point); and (8) time from onset to reperfusion $>4$ hours ( 1 point).

\section{Global left ventricular strain}

An ACUSON SC2000 ultrasound system (SIEMENS, Germany) was used, and the images were collected simultaneously with an electrocardiographic lead. All patients underwent echocardiography within 3 days after PCl. With the patient in a resting state, (1) a conventional series of standard cross-sections and (2) 3 apical 4-chamber, double-chamber and long-axis views were dynamically acquired; ECHO-PAC (GE Healthcare), a left ventricular quantification software, was used to automatically analyze the GLS of the myocardium (16-segment systems).

\section{Follow up}

All patients were followed up for 12 months until June 2021 by clinical visits or telephone calls. Major cardiovascular adverse events (MACE) in this study included unstable angina pectoris, non-fatal myocardial infarction, sudden cardiac death, and target vascular reconstruction (thrombolysis and coronary stent implantation). Once MACE occurred, follow-up was terminated. Patients who could not be contacted were considered lost to follow-up.

\section{Statistical analysis}

SPSS 19.0 (IBM, Armonk, NY, USA) was used for data analysis. Continuous variables were expressed as means \pm standard deviation (SD). Independent samples t-test was performed for between group comparisons, and one-way analysis of variance (ANOVA) followed by post-hoc LSD test for multiple group comparisons. The Cox regression model was used for multivariate analysis of clinical cardiovascular disease risk stratification. A receiver-operating characteristic (ROC) curve was constructed to evaluate the predictive value of MACE with different risk stratifications. The following three models were established to predict the risk of MACE: (1) TIMI risk score alone, (2) TIMI risk score+ GLS, and (3) TIMI risk score + GLS + clinical risk factors. The ability of each model to predict MACE was evaluated using the area under the ROC curve(MedCalc statistical software). A probability (p) value $<0.05$ was considered statistically significant.

\section{Results}

\section{General patient characteristics}


A total of 138 patients were included in this study. The patients were with 120 males (86.9\%) and 18 females $(13.1 \%)$. The mean patient age was $60.8 \pm 15.7$ years. Coronary arteriography (CAG) showed single-vessel disease in 28 patients (20.3\%), double-vessel disease in $56(40.6 \%)$, and triple-vessel disease in 54 (39.1\%). All baseline clinical characteristics of the patients, including sex, age, hypertension, diabetes history, blood lipid, TIMI risk score, and cardiac functions, are shown in Table 1. 
Table 1

General clinical characteristics of the patients

\begin{tabular}{|c|c|c|c|c|}
\hline Clinical variables & $\begin{array}{l}\text { All patients }(n= \\
138)\end{array}$ & $\begin{array}{l}\text { MACE } \\
(n=27)\end{array}$ & $\begin{array}{l}\text { Without MACE } \\
(n=111)\end{array}$ & $\mathbf{P}$ \\
\hline Male sex, n (\%) & $120(86.9 \%)$ & $24(88.9 \%)$ & $96(86.5 \%)$ & 0.862 \\
\hline Age, years & $60.78 \pm 15.69$ & $65.00 \pm 14.64$ & $59.76 \pm 15.83$ & 0.120 \\
\hline Diabetes mellitus, n (\%) & $36(26.2 \%)$ & $6(22.2 \%)$ & $30(27 \%)$ & 0.473 \\
\hline Hypertension, n (\%) & $76(55.1 \%)$ & $12(44.4 \%)$ & $64(57.7 \%)$ & 0.219 \\
\hline Treated vessel, n (\%) & & & & 0.112 \\
\hline Any left main & $28(20.3 \%)$ & $3(11.1 \%)$ & $25(22.5 \%)$ & \\
\hline Multi-vessel & $56(40.6 \%)$ & $10(37 \%)$ & $46(41.4 \%)$ & \\
\hline Triple-vessel & $54(39.1 \%)$ & $14(51.9 \%)$ & $40(34.2 \%)$ & \\
\hline $\begin{array}{l}\text { Time to admission, } \mathrm{n} \\
(\%)\end{array}$ & & & & 0.151 \\
\hline$<6$ & $89(64.5 \%)$ & $16(59.3 \%)$ & $73(65.8 \%)$ & \\
\hline$\geq 6$ & $49(35.5 \%)$ & $11(40.7 \%)$ & $38(32.1 \%)$ & \\
\hline TNT (IU/L) & $1.56 \pm 3.14$ & $2.95 \pm 5.83$ & $1.22 \pm 1.90$ & 0.009 \\
\hline CKMB & $31.61 \pm 6.38$ & $58.00 \pm 8.53$ & $25.19 \pm 5.60$ & 0.016 \\
\hline NT-proBNP (pg/ml) & $\begin{array}{l}262.5(97.75- \\
800.65)\end{array}$ & $\begin{array}{l}375.2(91.75- \\
1578.5)\end{array}$ & $\begin{array}{l}255(97.25- \\
731.25)\end{array}$ & 0.219 \\
\hline LVEDV(ml) & $113.88 \pm 30.13$ & $121.33 \pm 26.68$ & $112.07 \pm 30.74$ & 0.152 \\
\hline LVESV(ml) & $50.26 \pm 20.81$ & $57.07 \pm 22.88$ & $48.61 \pm 20.03$ & 0.058 \\
\hline LVEF (\%) & $56.52 \pm 8.26$ & $53.51 \pm 9.06$ & $57.25 \pm 7.93$ & 0.034 \\
\hline GLS & $-15.95 \pm 3.63$ & $-13.14 \pm 3.47$ & $-16.64 \pm 3.34$ & 0.001 \\
\hline TIMI & & & & 0.026 \\
\hline Low risk (0-3) & $89(64.5 \%)$ & $11(40.7 \%)$ & 78 (70.3\%) & \\
\hline Medium risk (4-6) & $40(29.0 \%)$ & $9(33.3 \%)$ & $31(27.9 \%)$ & \\
\hline high-risk (> 7) & $9(6.5 \%)$ & $7(25.9 \%)$ & $2(1.8 \%)$ & \\
\hline \multicolumn{5}{|c|}{$\begin{array}{l}\text { MACE: major cardiovascular adverse events; TNT: Troponin T; CK-MB: creative kinase-MB; NT-proBNP: } \\
\text { N-terminal pro-B-type natriuretic peptide; LVEF: left ventricular ejection fraction; LVEDV: left ventricular } \\
\text { end-diastolic volume; LVESV: left ventricular end-systolic volume; GLS: global longitudinal strain; } \\
\text { TIMI: thrombolysis in myocardial Infarction. }\end{array}$} \\
\hline
\end{tabular}


The patients were followed up for 12 months, and the median follow-up duration was 11 (range 2-12) months. During the followup period, 27 (19.6\%) patients developed MACE and 111 (80.4\%) did not, including unstable angina pectoris in 3 patients $(11.1 \%)$, heart failure in $5(25.9 \%)$, sudden cardiac death in $3(11.1 \%)$ and coronary stent implantation in 18 (66.7\%).

There were 11 cases (40.7\%), 9 cases (33.3\%), and 7 cases $(25.9 \%)$ in MACE group with a low, moderate and high TIMI risk score, respectively. There were 78 cases (70.3\%), 31 cases $(27.9 \%)$ and 2 cases $(1.8 \%)$ in the non-MACE group with a low, moderate and high TIMI risk score, respectively, and the difference was statistically significant. GLS was significantly higher in the non-MACE group compared with the MACE group $(-16.64 \pm 3.34$ vs. $-13.14 \pm 3.47, P<0.001)$.

Figure 1 illustrates the myocardial strain curve and bull's eye diagram of a patient with heart failure in the MACE group.

Figure 2 illustrates the myocardial strain curve and bull's eye diagram of a patient with good prognosis in the no-MACE group.

\section{Factors associated with MACE}

In multivariate analysis, Troponin T (TNT) (HR =1.117, 95\% confidence interval [Cl] 1.035-1.206; $\mathrm{P}=$ 0.004), LVEF (\%) (HR = 1.065, 95\% Cl 1.014-1.118; $\mathrm{P}=0.012)$, TIMI risk score $(\mathrm{HR}=1.273,95 \% \mathrm{Cl} 1.052-$ $1.540 ; \mathrm{P}=0.013), \mathrm{GLS}(\mathrm{HR}=1.312,95 \% \mathrm{Cl} 1.137-1.514 ; \mathrm{P}<0.001)$ (Table 2). 
Table 2

Univariate and multivariate analysis of MACE

\begin{tabular}{|c|c|c|c|c|c|c|}
\hline \multirow[t]{2}{*}{ Clinical variables } & \multicolumn{2}{|c|}{ Univariate } & \multicolumn{4}{|c|}{ multivariate Cox regression analysis } \\
\hline & HR & $\mathbf{P}$ & HR & $P$ value & $95 \% \mathrm{C}$ & \\
\hline Lower & \multicolumn{6}{|l|}{ Upper } \\
\hline TIMI & 1.371 & $<0.001$ & 1.273 & 0.013 & 1.052 & 1.540 \\
\hline \multicolumn{7}{|l|}{ risk score } \\
\hline EF & 0.959 & 0.045 & 1.065 & 0.012 & 1.014 & 1.118 \\
\hline LVEDV & 1.007 & 0.184 & & & & \\
\hline LVESV & 1.012 & 0.078 & & & & \\
\hline TNT & 1.011 & 0.002 & 1.117 & 0.004 & 1.035 & 1.206 \\
\hline CK-MB & 1.005 & 0.020 & & & & \\
\hline GLS & 1.268 & $<0.001$ & 1.312 & 0.001 & 1.137 & 1.514 \\
\hline $\begin{array}{l}\text { MACE: major carc } \\
\text { ventricular ejectio } \\
\text { systolic volume; }\end{array}$ & $\begin{array}{l}\text { radi } \\
\text { LVE } \\
\text { Ilon }\end{array}$ & $\begin{array}{l}\text { vents; T } \\
\text { t ventric } \\
\text { al straiı }\end{array}$ & $\begin{array}{l}\text { oponi } \\
\text { nd-dia } \\
\text { :Thro }\end{array}$ & $\begin{array}{l}\text { K-MB: cr } \\
\text { volume; } \\
\text { sis in M }\end{array}$ & $\begin{array}{l}\text { kinase-^ } \\
\text { l: left ve } \\
\text { lial Infa। }\end{array}$ & $\begin{array}{l}\text { VEF: lef } \\
\text { ular end } \\
\text { t. }\end{array}$ \\
\hline
\end{tabular}

\section{Predictive values of TIMI risk score and GLS in MACE}

The ROC curve analysis of the TIMI risk score (model 1), the TIMI risk score + GLS indicator (model 2), TIMI grading + GLS indicator + and clinical risk factors (model 3) showed the following: Model 1 (AUC $0.703,95 \% \mathrm{Cl} 0.579-0.828 \mathrm{P}=0.001)$ had a sensitivity of 0.519 and a specificity of 0.847 for predicting MACEs. Compared with model 1, model 2 (AUC: 0.810 vs $0.703, Z=2.223, P=0.026$ ) and model 3 (AUC: 0.815 vs $0.703, Z=2.261, P=0.024)$ had better value for predicting the occurrence of MACEs (Fig. 3 ).

\section{Discussion}

This study demonstrated that the value of GLS for predicting MACEs after PCI in STEMI patients is superior to that of LVEF and other clinical risk factors. Compared with the TIMI risk score alone, the TIMI risk score combined with GLS provides a more efficient risk assessment basis for predicting the prognosis of STEMI patients [14].

The TIMI risk score is a simple risk stratification tool. Many studies have confirmed that the TIMI score can be used to assess the short- and medium-term prognosis of STEMI patients [15-18]. STEMI patients with high TIMI scores at admission have a much higher probability of developing MACEs after discharge than those with low scores; thus, the TIMI score is an independent predictor of the occurrence of MACEs. The prognostic value of the TIMI risk score for predicting the risk of in-hospital mortality in STEMI 
patients (AUC $=0.803)[19]$, the 30-day mortality rate (in elderly people) $(A \cup C=0.67)[20]$ and the 1-year mortality rate $(A U C=0.73)[5]$ is not high, and it cannot be used to identify all high-risk patients. In our study, the prognostic value of the TIMI risk score for the occurrence of MACEs after 1 year was 0.703 , which is similar to the results of previous studies. Therefore, it is necessary to identify objective indicators to improve the discriminant ability of the TIMI risk score.

GLS can detect subtle changes in the myocardium after infarction, thereby more accurately assessing systolic function and providing additional prognostic information [21-23]. A considerable number of STEMI patients have undergone $\mathrm{PCl}$, and their LVEF is close to normal or may even remain unchanged; consequently, they are considered low-risk patients [24]. The absolute number of MACEs in STEMI patients with LVEF preservation is considerable .Previous studies [25] showed that patients with an LVEF $<40 \%$ had increased mortality and an increased incidence of MACE, massive hemorrhage and net adverse clinical event (NACE); furthermore, they reported that moderate left ventricular dysfunction was not a predictor of adverse clinical outcomes. In contrast, GLS improved the individualized risk stratification after STEMI, and in the population with known or suspected left ventricular dysfunction, GLS was superior to LVEF for predicting mortality. Therefore, compared to LVEF, GLS is a stronger predictor of MACEs [26-28].

This study further confirmed that GLS $(H R=1.312)$ was superior to LVEF and other clinical factors for predicting MACEs at 1 year. As the GLS level decreased, the risk of MACEs in STEMI patients increased significantly. The main pathophysiological explanations for this phenomenon are as follows: 1 . The left ventricular myocardium is a heterogeneous structure containing myocardial spirals and multilayered fibers; thinning of the myocardium occurs at the infarcted segments, and compensatory hypertrophy develops in the noninfarcted myocardium. Therefore, all segments are not uniform, and there are certain limitations in replacing the global cardiac systolic function as a volumetric measurement of LVEF with local myocardial function in the absence of changes in cardiac morphology. 2. Longitudinal fibers are the main component of the subendocardial myocardium, and the subendocardial myocardium is more susceptible to changes in ventricular pressure and coronary blood supply and more sensitive to ischemia than the midmyocardium and subepicardial myocardium [29]. Therefore, longitudinal stress is more sensitive to myocardial ischemia than other parameters (hoop, circumferential, and torsion stress) [29] and GLS has been shown to be a sensitive indicator of subclinical myocardial injury [30]. Although GLS can be used as a stable and sensitive indicator of cardiac function assessment, the clinical risk and prognosis of STEMI patients also differ due to differences in clinical characteristics [14]. Unless GLS is combined with the patient's clinical data, it cannot provide a sufficient prediction of the prognosis.

This study showed that compared with the TIMI risk score alone, the GLS combined with the TIMI risk score (AUC: 0.810 vs 0.703 ) and the GLS and TnT combined with the TIMI risk score (AUC: 0.815 vs 0.703) had better predictive power. (Fig. 3). However, there was no significant difference between the TIMI risk score combined with GLS and the TIMI risk score combined with GLS and clinical risk factors. Comparatively speaking, the TIMI risk score combined with GLS was more efficient and effective in clinical application, which can accurately predict the occurrence of MACE. 
In contrast, TIMI combined with GLS is more efficient and convenient in clinical application. The main reasons for this are as follows: 1) The TIMI risk score provides a comprehensive reference for patients' clinical risk factors. It is highly subjective and lacks objective variables; especially for patients with atypical clinical symptoms and no characteristic ECG manifestations, it often underestimates the risk of disease [20]. 2) As an objective indicator of high-quality cardiac function evaluation, GLS is far superior to LVEF for predicting MACE. The inclusion of GLS in the TIMI risk score provides complementary advantages.

This study has the following limitations: (1) The sample size is small, and the influencing factors of the included studies are few. To confirm the effectiveness of the optimized combination indicators in this study for predicting the prognosis of STEMI patients, it is necessary to increase the sample size and conduct longer-term studies. (2) In this study, only a single GLS indicator was used. We should further study the guiding significance of different myocardial strain parameters in different periods on long-term prognosis while extending the follow-up time.

\section{Conclusions}

The present study demonstrated thatGLS is superior to LVEF and other clinical risk factors in predicting major adverse cardiac events in STEMI patients after PCl; Compared with TIMI risk score alone, the TIMI risk score combined with GLS has higher predictive power and provides a more efficient risk assessment basis for determining the prognosis of STEMI patients.

\section{Declarations}

\section{Author information}

\section{Affiliations}

Department of Cardiology,Jiading District Central Hospital Affiliated Shanghai University of Medicine \&Health Sciences

Jin-Rong Lou \& Feng Zhu

\section{Contributions}

WYZ and JW conducted the literature searches and provided summaries of previous studies. ML and DBY acquired the data, performed statistical analyses, and drafted the manuscript. JLL and YCW contributed to development of the protocol and the interpretation of results. All authors contributed to and have approved the final version of the manuscript.

\section{Corresponding author}

Correspondence to Min Lu 


\section{Ethics declarations}

\section{Conflict of interest}

The authors declare that they have no conflict of interest to disclose.

\section{Consent to publication}

Verbal consent obtained. No patient-identifiable data included.

\section{Additional information}

\section{Code availability}

The datasets used and/or analysed during the current study are available from the corresponding author on reasonable request.

\section{Funding}

The study received a research grant from Jiading District Health and Family Planning Commission Research Project (NO. JDKW-2020-0023) and the Key Medical Discipline of Jiading District, Shanghai (No. 2020-jdyxdzk-02).

\section{References}

1. Yadlapati A, Gajjar M, Schimmel DR, Ricciardi MJ, Flaherty JD (2016) Contemporary management of ST-segment elevation myocardial infarction. Intern Emerg Med 11:1107-1113. https://doi.org/10.1007/s11739-016-1550-3

2. Ibanez B, James S, Agewall S, et al (2018) 2017 ESC guidelines for the management of acute myocardial infarction in patients presenting with ST-segment elevation: the task force for the management of acute myocardial infarction in patients presenting with ST-segment elevation of the European society of cardiology (ESC). Eur Heart J 39:119-177. https://doi.org/10.1093/eurheartj/ehx393

3. Selvarajah S, Fong AY, Selvaraj G, Haniff J, Uiterwaal CS, Bots ML (2012) An Asian validation of the TIMI risk score for ST-segment elevation myocardial infarction. PLoS One 7:e40249. https://doi.org/10.1371/journal.pone.0040249

4. Damman P, Woudstra P, Kuijt WJ, Kikkert WJ, van de Hoef TP, Grundeken MJ, Harskamp RE, Henriques JP, Piek JJ, Tijssen JG, de Winter RJ (2013) Short- and long-term prognostic value of the TIMI risk score after primary percutaneous coronary intervention for ST-segment elevation myocardial infarction. J Interv Cardiol 26:8-13. https://doi.org/10.1111/j.1540-8183.2012.00763.x

5. Littnerova S, Kala P, Jarkovsky J, Kubkova L, Prymusova K, Kubena P, Tesak M, Toman O, Poloczek M, Spinar J, Dusek L, Parenica J (2015) GRACE score among six risk scoring systems (CADILLAC, 
PAMI, TIMI, Dynamic TIMI, Zwolle) demonstrated the best predictive value for prediction of long-term mortality in patients with ST-elevation myocardial infarction. PLoS One 10:e0123215. https://doi.org/10.1371/journal.pone.0123215

6. Amsterdam EA, Wenger NK, Brindis RG et al (2014) 2014 AHA/ACC guideline for the management of patients with non-ST-elevation acute coronary syndromes: a report of the American college of cardiology/American heart association task force on practice guidelines. J Am Coll Cardiol 64:e139e228. https://doi.org/10.1016/j.jacc.2014.09.017

7. Roffı M, Patrono C, Collet JP et al (2016) 2015 ESC Guidelines for the management of acute coronary syndromes in patients presenting without persistent ST-segment elevation: task Force for the management of acute coronary syndromes in patients presenting without persistent ST-segment elevation of the european society of cardiology (ESC). Eur Heart J 37:267-315. https://doi.org/10.1093/eurheartj/ehv320

8. Mor-Avi V, Lang RM, Badano LP et al (2011) Current and evolving echocardiographic techniques for the quantitative evaluation of cardiac mechanics: ASE/EAE consensus statement on methodology and indications endorsed by the Japanese society of echocardiography. J Am Soc Echocardiogr 24:277-313. https://doi.org/10.1016/j.echo.2011.01.015

9. Wei XB, Liu YH, He PC, Jiang L, Zhou YL, Chen JY, Tan N, Yu DQ (2017) Additive prognostic value of left ventricular ejection fraction to the TIMI risk score for in-hospital and long-term mortality in patients with ST segment elevation myocardial infarction. J Thromb Thrombolysis 43:1-6. https://doi.org/10.1007/s11239-016-1407-7

10. Potter E, Marwick TH (2018) Assessment of left ventricular function by echocardiography: the case for routinely adding global longitudinal strain to ejection fraction. JACC Cardiovasc Imaging 11:260274. https://doi.org/10.1016/j.jcmg.2017.11.017

11. Møller JE, Hillis GS, Oh JK, Reeder GS, Gersh BJ, Pellikka PA (2006) Wall motion score index and ejection fraction for risk stratification after acute myocardial infarction. Am Heart J 151:419-425. https://doi.org/10.1016/j.ahj.2005.03.042

12. Thune JJ, Køber L, Pfeffer MA, Skali H, Anavekar NS, Bourgoun M, Ghali JK, Arnold JM, Velazquez EJ, Solomon SD (2006) Comparison of regional versus global assessment of left ventricular function in patients with left ventricular dysfunction, heart failure, or both after myocardial infarction: the valsartan in acute myocardial infarction echocardiographic study. J Am Soc Echocardiogr 19:14621465. https://doi.org/10.1016/j.echo.2006.05.028

13. Lang RM, Badano LP, Mor-Avi V et al (2015) Recommendations for cardiac chamber quantification by echocardiography in adults: an update from the American society of echocardiography and the European association of cardiovascular imaging. J Am Soc Echocardiogr 28:1-39.e14. https://doi.org/10.1016/j.echo.2014.10.003

14. Gevaert SA, De Bacquer D, Evrard P et al (2014) Gender, TIMI risk score and in-hospital mortality in STEMI patients undergoing primary PCI: results from the Belgian STEMI registry. Eurolntervention 9:1095-1101. https://doi.org/10.4244/eijv9i9a184 
15. Mok Y, Ballew SH, Bash LD et al (2018) International validation of the thrombolysis in myocardial infarction (TIMI) risk score for secondary prevention in post-mi patients: a collaborative analysis of the chronic kidney disease prognosis consortium and the risk validation scientific committee. J Am Heart Assoc 7:e008426. https://doi.org/10.1161/jaha.117.008426

16. Morrow DA, Antman EM, Snapinn SM, McCabe CH, Theroux P, Braunwald E (2002) An integrated clinical approach to predicting the benefit of tirofiban in non-ST elevation acute coronary syndromes. Application of the TIMI risk score for UA/NSTEMI in PRISM-PLUS. Eur Heart J 23:223-229. https://doi.org/10.1053/euhj.2001.2738

17. Scirica BM, Cannon CP, Antman EM, Murphy SA, Morrow DA, Sabatine MS, McCabe CH, Gibson CM, Braunwald E (2002) Validation of the thrombolysis in myocardial infarction (TIMI) risk score for unstable angina pectoris and non-ST-elevation myocardial infarction in the TIMI III registry. Am J Cardiol 90:303-305. https://doi.org/10.1016/s0002-9149(02)02468-2

18. Samaha FF, Kimmel SE, Kizer JR, Goyal A, Wade M, Boden WE (2002) Usefulness of the TIMI risk score in predicting both short- and long-term outcomes in the veterans affairs non-Q-wave myocardial infarction strategies in-hospital (VANQWISH) trial. Am J Cardiol 90:922-926. https://doi.org/10.1016/s0002-9149(02)02654-1

19. González-Pacheco H, Arias-Mendoza A, Álvarez-Sangabriel A, Juárez-Herrera Ú, Damas F, Eid-Lidt G, Azar-Manzur F, Martínez-Sánchez C (2012) The TIMI risk score for STEMI predicts in-hospital mortality and adverse events in patients without cardiogenic shock undergoing primary angioplasty. Arch Cardiol Mex 82:7-13

20. He SJ, Weng JX, Chen HJ, Li HQ, Guo WQ, Cao Q, Xu S, Yan HB, Peng CN (2021) The prognostic value of MELD-XI in elderly patients with ST-segment elevation myocardial infarction: an observational study. BMC Cardiovasc Disord 21:53. https://doi.org/10.1186/s12872-021-01862-5

21. Smiseth OA, Torp H, Opdahl A, Haugaa KH, Urheim S (2016) Myocardial strain imaging: how useful is it in clinical decision making? Eur Heart J 37:1196-1207. https://doi.org/10.1093/eurheartj/ehv529

22. ErsbøII M, Valeur N, Mogensen UM, Andersen MJ, Møller JE, Velazquez EJ, Hassager C, Søgaard P, Køber L (2013) Prediction of all-cause mortality and heart failure admissions from global left ventricular longitudinal strain in patients with acute myocardial infarction and preserved left ventricular ejection fraction. J Am Coll Cardiol 61:2365-2373. https://doi.org/10.1016/j.jacc.2013.02.061

23. Kammerlander AA, Donà $C$, Nitsche $C$ et al (2020) Feature tracking of global longitudinal strain by using cardiovascular MRI improves risk stratification in heart failure with preserved ejection fraction. Radiology 296:290-298. https://doi.org/10.1148/radiol.2020200195

24. Hanania G, Cambou JP, Guéret P, Vaur L, Blanchard D, Lablanche JM, Boutalbi Y, Humbert R, Clerson $P$, Genès N, Danchin N (2004) Management and in-hospital outcome of patients with acute myocardial infarction admitted to intensive care units at the turn of the century: results from the French Nationwide USIC 2000 registry. Heart 90:1404-1410.

https://doi.org/10.1136/hrt.2003.025460

Page $13 / 17$ 
25. Ng VG, Lansky AJ, Meller S, Witzenbichler B, Guagliumi G, Peruga JZ, Brodie B, Shah R, Mehran R, Stone GW (2014) The prognostic importance of left ventricular function in patients with ST-segment elevation myocardial infarction: the HORIZONS-AMI trial. Eur Heart J Acute Cardiovasc Care 3:6777. https://doi.org/10.1177/2048872613507149

26. Curtis JP, Sokol SI, Wang Y, Rathore SS, Ko DT, Jadbabaie F, Portnay EL, Marshalko SJ, Radford MJ, Krumholz HM (2003) The association of left ventricular ejection fraction, mortality, and cause of death in stable outpatients with heart failure. J Am Coll Cardiol 42:736-742. https://doi.org/10.1016/s0735-1097(03)00789-7

27. Sengeløv M, Jørgensen PG, Jensen JS, Bruun NE, Olsen FJ, Fritz-Hansen T, Nochioka K, BieringSørensen T (2015) Global longitudinal strain is a superior predictor of all-cause mortality in heart failure with reduced ejection fraction. JACC Cardiovasc Imaging 8:1351-1359. https://doi.org/10.1016/j.jcmg.2015.07.013

28. Reindl M, Tiller C, Holzknecht $M$ et al (2019) Prognostic implications of global longitudinal strain by feature-tracking cardiac magnetic resonance in ST-elevation myocardial infarction. Circ Cardiovasc Imaging 12:e009404. https://doi.org/10.1161/circimaging.119.009404

29. Urbano-Moral JA, Arias-Godinez JA, Ahmad R, Malik R, Kiernan MS, DeNofrio D, Pandian NG, Patel AR (2013) Evaluation of myocardial mechanics with three-dimensional speckle tracking echocardiography in heart transplant recipients: comparison with two-dimensional speckle tracking and relationship with clinical variables. Eur Heart J Cardiovasc Imaging 14:1167-1173. https://doi.org/10.1093/ehjci/jet065

30. Luo Y, Liu Y, Guan X, Zhang Y, Li J (2018) Value of three dimensional-speckle tracking imaging for predicting left ventricular function after non-ST-segment elevation myocardial infarction with percutaneous coronary intervention. J Xray Sci Technol 26:331-339. https://doi.org/10.3233/xst17316

\section{Figures}



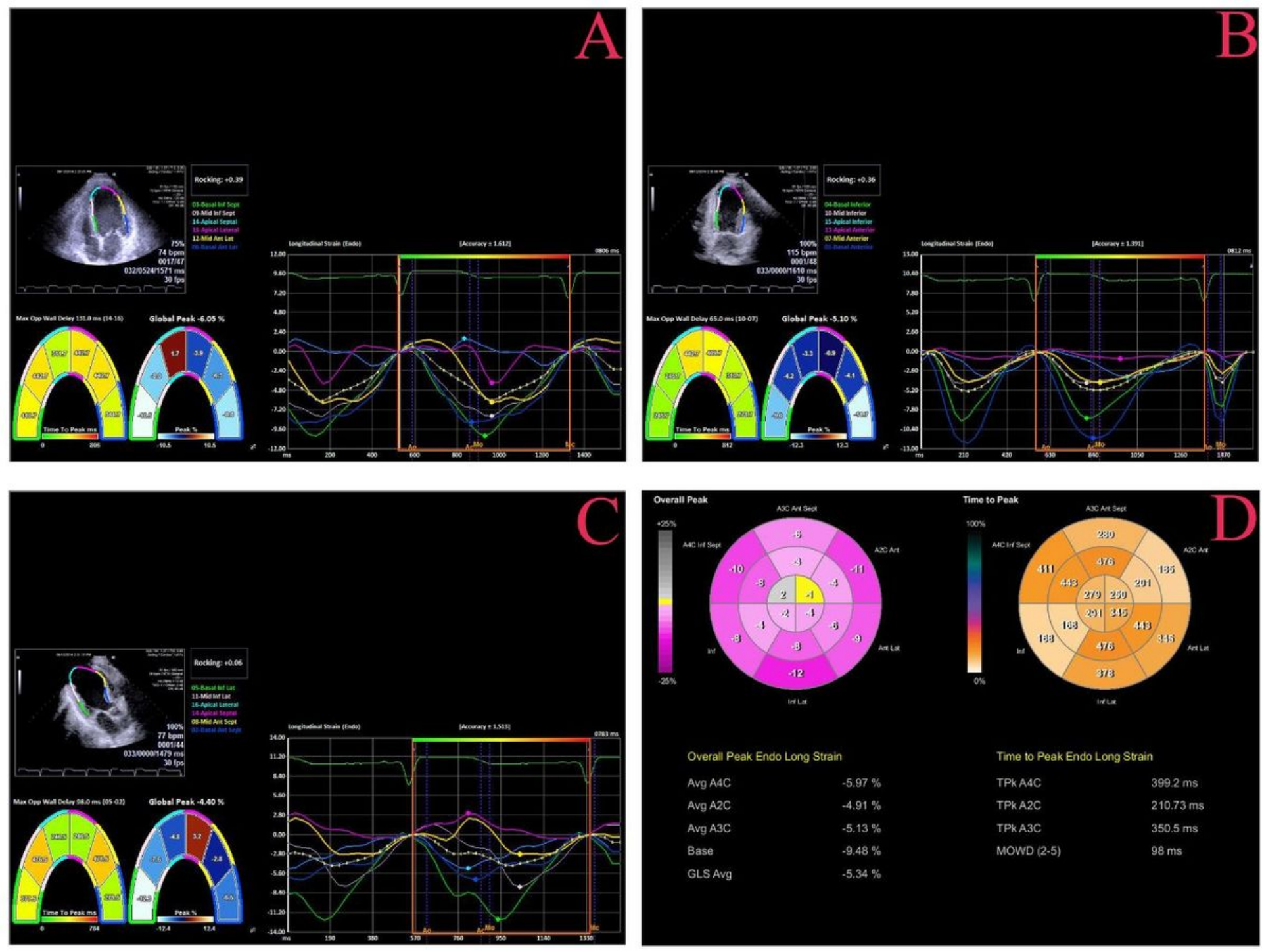

\section{Figure 1}

The myocardial strain curve and bull's eye diagram of a patient with heart failure $n$ the MACE group. The global longitudinal strain was reduced to $-5.34 \%$. This figure also shows the spatial and temporal changes of the A4C (a), A2C (b), A3C (c) views and bovine eye diagram (d) 

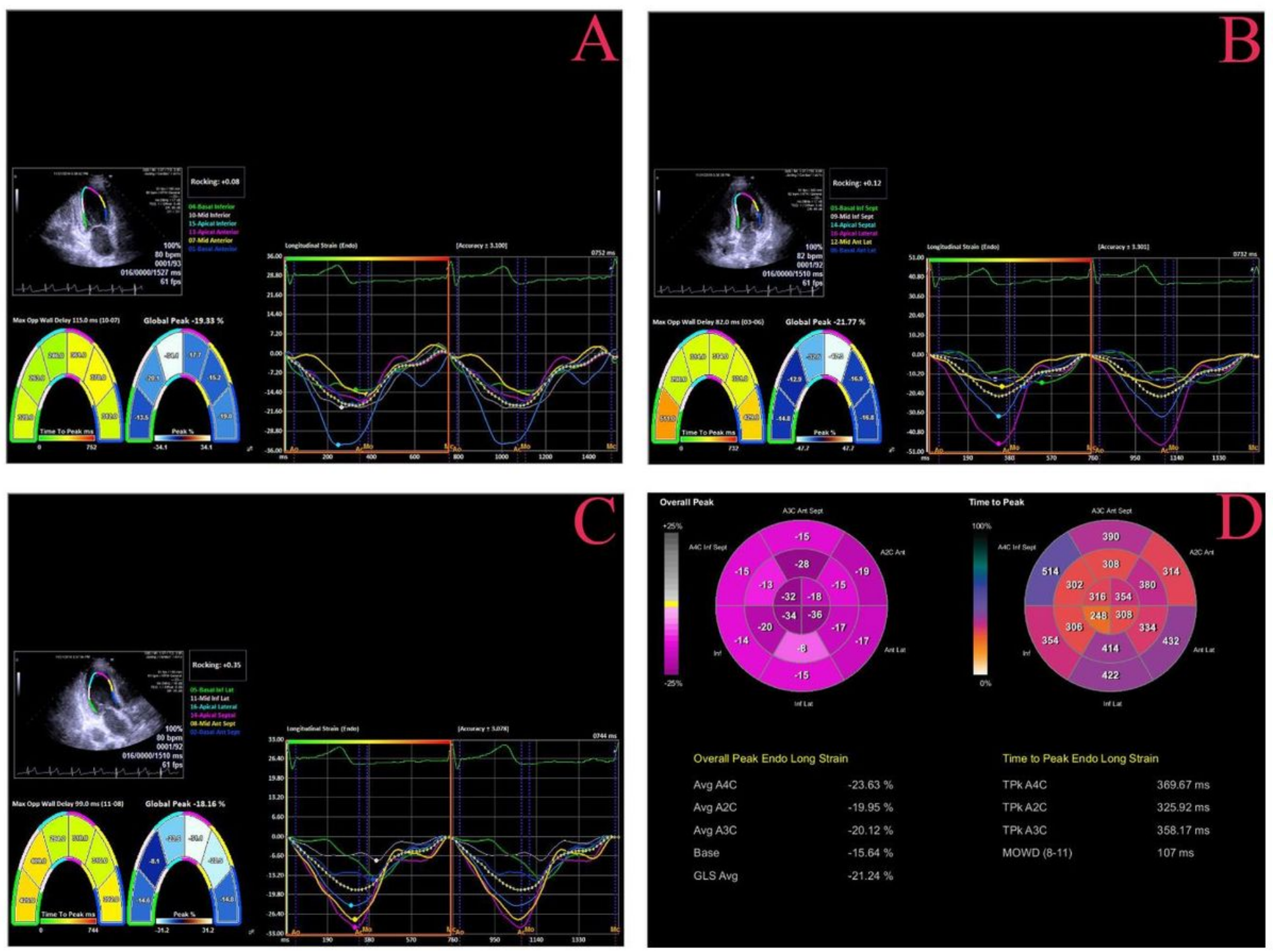

\section{Figure 2}

The myocardial strain curve and bull's eye diagram of a patient with good prognosis In the no-MACE group. The global longitudinal strain was $-21.24 \%$. This figure also shows the spatial and temporal changes in the A4C (a), A2C (b), A3C (c) views and bovine eye diagram (d) 


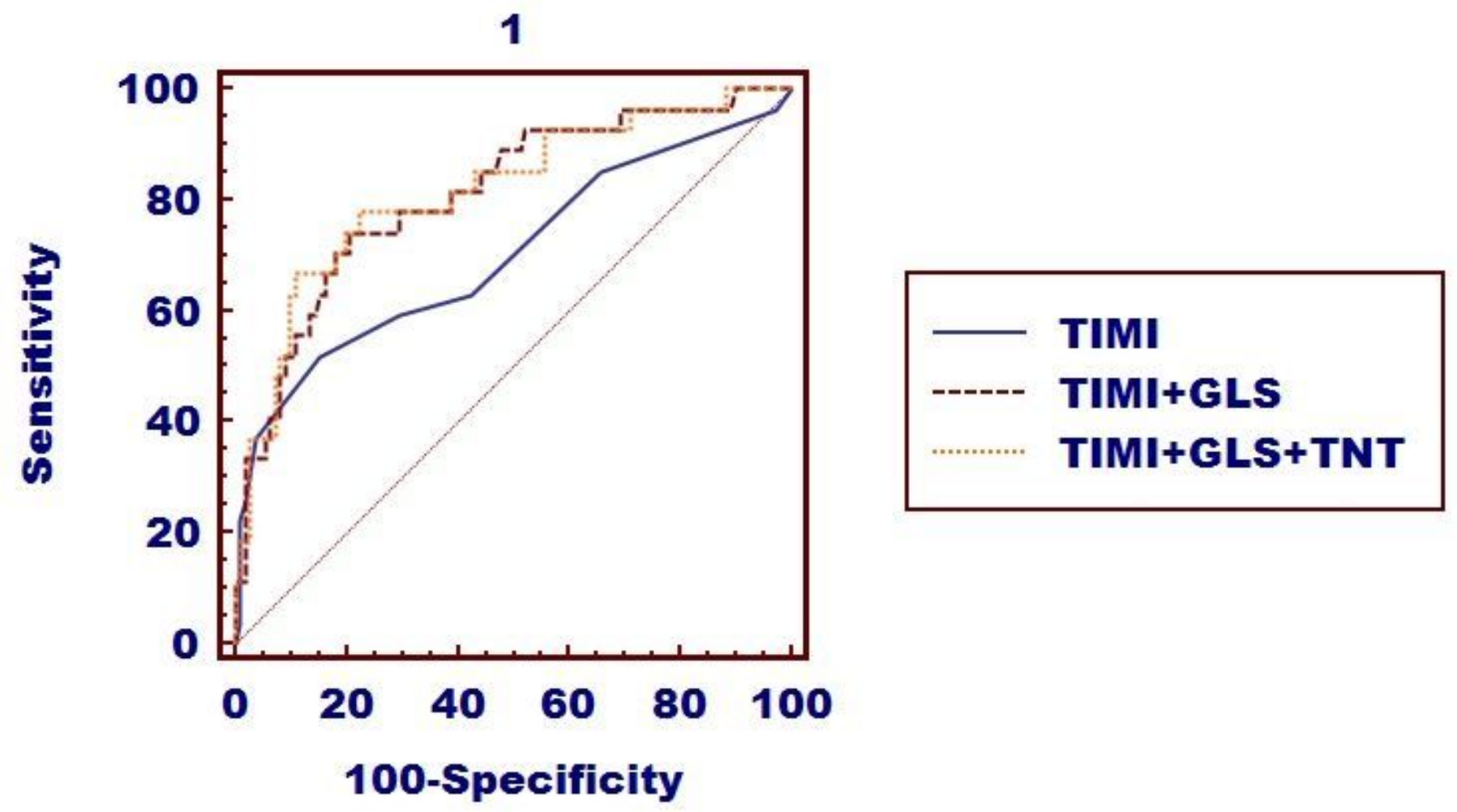

Figure 3

The AUCs in the model 2 (AUC=0.810) and model $3(A U C=0.815)$ were significantly higher than model 1 $(p<0.001)$. However, there was no significant difference between model 2 and model $3(p=0.82)$. Model 1 : the TIMI risk score alone, model 2: the TIMI risk score + GLS ; model 3: TIMI risk score combined with GLS and clinical risk factors 